\title{
A Qualitative Analysis of the Impact of Carboplatin AUC 10 on Physical, Work Functioning and Bone Marrow Toxicity Among Seminoma Patients - A Single-centre Experience
}

\author{
MARINA MILIC ${ }^{1}$, MARCIA HALL ${ }^{1}$, ANNETTE HAWKINS ${ }^{1}$, ANDREW GOGBASHIAN ${ }^{2}$, \\ GORDON RUSTIN ${ }^{1 *}$ and ANAND SHARMA ${ }^{1 *}$ \\ ${ }^{1}$ Department of Medical Oncology, Mount Vernon Cancer Centre, Northwood, U.K.; \\ ${ }^{2}$ Department of Radiology, Mount Vernon Cancer Centre, Paul Strickland Scanner Centre, Northwood, U.K.
}

\begin{abstract}
Background: Single-agent carboplatin at area under the curve 10 (AUC10) is an effective treatment for metastatic seminoma. As far as we are aware of, there have been no studies reporting its effects on short-term quality of life. The objective was to study the efficacy, safety and tolerability, using health-related quality of life, of carboplatin AUC10 chemotherapy in patients with metastatic seminoma. Patients and Methods: Forty-four patients with metastatic seminoma treated at Mount Vernon Cancer Centre with carboplatin AUC10 were included in this study. Response to treatment was determined by radiological imaging (Response Evaluation Criteria in Solid Tumors $v$ 1.1) and serum tumour markers. Toxicities were evaluated using the Common Terminology Criteria for Adverse Events Version 4.0. Quality of life treatment-related toxicities were assessed during treatment at pre-chemotherapy assessments. After treatment, toxicity was assessed using a defined telephone questionnaire consisting of four questions relating to hair loss, hearing impairment, days absent from work, and neuropathy. Results: At a median follow-up of 27.5 (range=4-84) months, no patient had experienced relapse. Grade 3/4 neutropenia was seen in 15 (35\%) patients, nine (21\%) required prophylactic granulocyte colony-stimulating factor, 13 (30\%) patients had grade 3/4 thrombocytopenia. Commonest non-haematological toxicities were fatigue in 28
\end{abstract}

This article is freely accessible online.

*These Authors share last authorship.

Correspondence to: Dr. Anand Sharma, Department of Medical Oncology, Mount Vernon Cancer Centre, Northwood, HA6 2RN, U.K.E-mail: anand.sharma3@nhs.net

Key Words: Seminoma, bone marrow, carboplatin, work functioning, toxicity.
(65\%) and nausea $14(33 \%)$ patients. They were grade 1 in $82 \%$ and $92 \%$ of cases, respectively. Six out of 44 (14\%) had residual tinnitus. One patient had residual grade 1 peripheral neuropathy. Ten patients continued to work throughout treatment and two patients were retired. Of the remaining patients, 16 (37\%), took fewer than 5 days off work. Conclusion: Carboplatin AUC10 is a safe and effective treatment for stage II/III seminoma with better health-related quality of life than experienced with combination cisplatin-based chemotherapy.

Germ cell tumours of the testis are classified as seminoma (approximately 50\%) or non-seminomatous tumours (embryonal, teratoma, choriocarcinoma, yolk sac tumours and mixed histology). Around $85 \%$ of men with seminoma present with stage 1 and $10 \%$ with stage II disease (1). Of men with stage I seminoma, $15 \%$ will experience relapse following orchidectomy. Active surveillance is generally recommended for patients with stage I disease as a strategy to minimize treating the majority who are already cured by surgery alone $(2,3)$. Risk factors potentially indicating a higher risk of relapse in stage I include tumour size $>4 \mathrm{~cm}$, lymphovascular invasion and involvement of the rete testes (4).

Cisplatin-based combination chemotherapy (bleomycin, cisplatin and etoposide; BEP) has been considered the main treatment strategy for metastatic seminoma. More recently it has been shown that 3-4 cycles of single-agent carboplatin [at area under the curve 10 (AUC10)] (5-11), has a similar efficacy. As treatment for metastatic seminoma is now so successful and most patients will become long-term survivors, the impact of short- and long-term toxicities of this treatment on patient quality of life has become paramount. Other factors such as length of treatments, convenience and cost also play an increasingly important role in patient's decision making, if offered a choice between combination cisplatin-based therapy and single-agent carboplatin. 
The most important short-term toxicity of carboplatin is haematological toxicity, with a reported incidence of $70 \%$, $54 \%$ and $26 \%$ of grade $3 / 4$ neutropenia, thrombocytopenia and anaemia, respectively (9). Obvious immediate effects of chemotherapy range from changes in personal appearance (hair loss) to fatigue, which may have an impact on employment and social life. Adverse effects such as neuropathy and tinnitus can also be very debilitating and more so perhaps for young adults commonly affected by seminoma, whose peers are all likely to be in good health. Approximately $10 \%$ will suffer significant psychosocial problems (12). Although many studies have looked into long-term psychosocial aspects of chemotherapy, none have explored short-term toxicities and effects on social life during chemotherapy (13-15).

Here we studied the efficacy, safety and tolerability of carboplatin AUC10 chemotherapy and explored healthrelated quality of life in patients with metastatic seminoma during and immediately following their chemotherapy.

\section{Patients and Methods}

All patients with metastatic seminoma treated with carboplatin AUC10 between 2010 and 2017 were identified from treatment databases at our centre. Data were collected retrospectively and staging assessed using the seventh edition of the TNM classification (16) with computed tomographic (CT) imaging of the chest, abdomen and pelvis [Response Evaluation Criteria in Solid Tumours (RECIST) 1.1] (17) and serum tumour markers alpha foeto-protein (AFP), human chorionic gonadotropin hormone ( $\beta$-HCG) and lactate dehydrogenase (LDH) when available. Appropriate approvals were received from the hospital Ethics Committee (Audit number 15541).

Carboplatin dosing (AUC10) was calculated using the Calvert formula [total dose in $\mathrm{mg}=$ target AUC (glomerular filtration rate $\mathrm{ml} / \mathrm{min}+25)$ ]. An accurate estimation of glomerular filtration rate was obtained for every patient before treatment using ${ }^{51} \mathrm{Cr}$-labelled ethylenediamine tetra-acetic acid (EDTA) clearance (18). The doses were not capped for the initial treatment. Treatment was administered as a single dose every 21 days for three or four cycles.

Response to treatment was determined by radiological imaging and serum tumour markers. Toxicities were evaluated using the Common Terminology Criteria for Adverse Events (CTCAE) Version 4.1 Quality of life (QoL) and intermediate treatment-related toxicities were assessed post treatment using a self-designed telephone questionnaire consisting of four questions about toxicity, which included hair loss, hearing impairment, days absent from work, and neuropathy.

Response to treatment was assessed after three cycles of carboplatin AUC10. If complete response to treatment was achieved, no further treatment was given. In the case of partial response, a fourth cycle of carboplatin was administered. Residual para-aortic lymphadenopathy was considered for subsequent retroperitoneal lymph node dissection (RPLND).

Dose reduction was considered based on the grade of haematological toxicity and the clinical assessment. No prophylactic G-CSF was routinely used with the first cycle; however, it was added to second and subsequent cycles if there were dose delays or greater than grade 1 neutropenia on day 21. Blood product support was available as required according to local protocols. No dose recalculation of carboplatin was performed after the initial dosing based on EDTA.

All patients underwent full blood count, liver function tests, urea, electrolyte, AFP and HCG determinations prior to each cycle. A CT scan of the chest, abdomen and pelvis was performed prior to starting treatment and after cycle 3 . Repeat CT imaging of the abdomen was considered 6 weeks following treatment completion in those who only obtained partial responses after three cycles, prior to recommending RPLND.

If serum tumour markers were not elevated prior to treatment, response was determined according to RECIST criteria alone. Complete response (CR) was defined as complete resolution of disease on imaging (reduction of any enlarged lymph nodes to short axis of under $1 \mathrm{~cm}$ ) and normalization of serum tumour markers. Partial response was defined as more than $30 \%$ reduction in the target lesions; progressive disease was determined by a combination of progressive disease on imaging with/without a rise in serum tumour markers (19). Toxicities were evaluated using CTCAE version 4.1 and recorded during treatment but data were collected retrospectively (20).

Patients were followed-up every 3 months in the first year, every 4 months in the second year, 6-monthly in the third year and annually thereafter. A full blood count, renal function, liver function tests with serum tumour markers (AFP, HCG, LDH) were performed at each visit. CT imaging of the abdomen (retroperitoneum) alone, unless other sites of disease were documented prior to treatment, was carried out at the end of treatment and annually for 2 years post chemotherapy.

Short and intermediate follow-up QoL was assessed using a locally designed questionnaire. based on the CTCAE $\mathrm{v} 1.0$ toxicity assessments. Questions were put directly to patients on treatment at the clinic and, where possible, when attending for follow-up appointments. To complete the dataset, however, some patients were questioned over the telephone if the follow-up QoL data were missing.

\section{Results}

A total of 44 patients, with a median age of 44 (range=26-77) years, were treated at Mount Vernon Cancer Centre between 2010 and 2017. Twenty patients had stage IIA, 17 stage IIB, five stage IIC and two stage III disease. Of these, 17 (39\%) patients had stage 1 disease at diagnosis. The average dose of carboplatin administered per cycle was $1240 \mathrm{mg}$ (range $=800$ $1,800 \mathrm{mg})$. The tumour markers were as follows- $\mathrm{LDH}$ elevated in 17 (39\%), HCG in nine $(21 \%)$ patients, one patient had persistently raised AFP, which was unrelated to his disease. Carboplatin was given in two, three and four cycles to $4.3 \%$, $87 \%$ and $8.7 \%$ patients, respectively. The four patients who required a fourth cycle of carboplatin all had stage IIc disease. Following this, two patients who had their initial diagnosis made on node biopsies underwent RPLND, with histology showing necrosis, and two required close surveillance of residual para-aortic lymphadenopathy, which resolved on follow-up. There was no evidence of disease relapse at a median follow-up of 27.5 (range=4-84) months. Data regarding haematological toxicity were available for all patients and are 
reported in Table I. Grade 3 and 4 neutropenia and thrombocytopenia were experienced by $3(7 \%)$ and $11(23 \%)$ patients respectively. Nine $(21 \%)$ required prophylactic G-CSF in total, with four after their first cycle and five after cycle 2. Thirteen patients (30\%) had grade 3/4 thrombocytopenia. There was only one hospital admission for neutropenic sepsis.

Five patients required a single cycle of chemotherapy to be delayed by 1 week, four of these as a result of haematological toxicity. Overall, 10 patients needed reductions in chemotherapy doses for neutropenia/thrombocytopenia, by $10 \%$ in six patients and $20 \%$ for another five, following which there were no further dose reductions or treatment delays. A single patient required a blood transfusion and only two patients were admitted, one for intravenous anti-emetics and the other for neutropenic sepsis.

The most common non-haematological toxicity was fatigue, which was seen in $65 \%$ of the treated patients, with grade 1 fatigue seen in 23/28 cases (Table II). Nausea was less common, seen in $14(33 \%)$ patients, with grade 1 symptoms in 13/14 cases. Mild Grade 1 tinnitus affected six (14\%) patients, and one suffered grade 3, while only one patient suffered mild hearing loss. Forty out of 44 (93\%) patients had no residual tinnitus. Regrettably, hearing loss was not formally tested in this cohort of patients, but is not very common in relation to carboplatin, unlike cisplatin treatment, with a reported incidence of $20-50 \%$ hearing loss (21-23). Two patients had minimal hair loss during their treatment. One patient had residual grade 1 peripheral neuropathy. Out of the 44 patients, 10 (23\%) patients continued to work throughout their treatment, not having to take any full days off at all, including their treatment day. Sixteen (37\%) took fewer than 5 days off work, four (9\%) patients took between 5-21 days and 13 patients more than 21 days (range 21 to 90 days), including two patients who were already retired.

\section{Discussion}

Whilst radiation had been the standard treatment for earlystage seminoma for many years, growing concerns about long-term toxicities in patients with this highly curative disease prompted additional treatment strategies to be pursued in order to minimize long-term morbidity and mortality attributable to treatment $(24,25)$.

Platinum-based chemotherapy has gained gradual popularity both in early and advanced disease based on increasing evidence that this is more effective than radiotherapy in stage II seminoma and associated with an improved toxicity profile. Originally, Horwich et al. reported a study of 70 patients with metastatic seminoma treated with single-agent carboplatin at $400 \mathrm{mg} / \mathrm{m}^{2}$ (analogous to AUC6) with 3-year survival rate of $91 \%$, but $22 \%$ patients experienced relapse and required salvage therapy (5). By
Table I. Haematological toxicity.

\begin{tabular}{lcccc}
\hline Blood element & Grade 1 & Grade 2 & Grade 3 & Grade 4/5 \\
\hline Neutrophil count & 0 & 9 & 3 & 0 \\
Platelet count & 3 & 8 & 10 & 0 \\
Hb & 0 & 0 & 1 & 0 \\
Febrile neutropenia & 0 & 0 & 1 & 0 \\
\hline
\end{tabular}

Table II. Non-haematological toxicities seen in patients on carboplatin AUC10.

\begin{tabular}{lcccc}
\hline & Grade 1 & Grade 2 & Grade 3 & Total \\
\hline Fatigue & 23 & 5 & 0 & $28(56 \%)$ \\
Nausea & 13 & 1 & 0 & $14(28 \%)$ \\
Tinnitus & 6 & 0 & 0 & $5(12 \%)$ \\
Vomiting & 0 & 1 & 1 & $2(4 \%)$ \\
\hline
\end{tabular}

contrast, the Spanish Germ Cell Cancer Group Study reported treating stage IIA or IIB seminoma with four cycles of cisplatin and etoposide or three cycles of BEP chemotherapy in 2008 and showed no relapses among 72 patients (26). Subsequently two randomized controlled trials failed to demonstrate equivalence or superiority of singleagent carboplatin AUC7 compared to cisplatin-based regimens (8). The Medical Research Council UK trial, although underpowered to show equivalence, demonstrated no statistically significant differences in major survival endpoints when comparing single-agent carboplatin at a dose of $400 \mathrm{mg} / \mathrm{m}^{2}$ to etoposide and cisplatin $(27,28)$. Krege et $a l$. also investigated the use of single-agent carboplatin at a dose of AUC7, but as an alternative to radiotherapy in stage IIA/B disease in a prospective phase II trial. Again, an overall relapse rate of $18 \%$, with a median time to relapse of 6 months failed to better relapse rates seen with radiotherapy but did demonstrate a significantly lower toxicity profile (29, 30). The findings of these trials, particularly the inability of single-agent carboplatin at AUC7 to improve on radiotherapy or cisplatin combinations, resulted in BEP becoming the standard treatment for patients with metastatic seminoma, as well as good prognosis for those with teratoma/mixed germ cell tumour.

In vitro work suggested that there may be a dose-response effect with carboplatin in seminoma (31). This information and the significant toxicity related to BEP, led the Orchid Clinical Trials collaborative group to support a pilot study where patients with good prognosis metastatic seminoma were offered even higher carboplatin dose at AUC10 (27). This successfully reported a failure rate of only $5 \%$, but in a study 
of only in 20 patients. Validation of these superior results in 61 further patients treated with carboplatin at AUC10, with a 3 -year overall survival) of $96.2 \%$ and progression-free survival) of $93.2 \%$, confirmed significantly less toxicity compared to both combination regimens and radiotherapy (9).

Despite the numerous studies detailed above, no publication has reported detailed toxicity data for these patients. We demonstrate that carboplatin at AUC10 is a safe regimen as reflected by the absence of an adverse haematological profile.

In our cohort of patients, G-CSF prophylaxis was required in $20 \%$ of the patients and there was only one episode of neutropenic sepsis. This is very similar to toxicity data published by Tookman et al., where $23 \%$ of patients required prophylactic G-CSF, with a single admission for febrile neutropenia (9).

Most importantly, patients were able to preserve their physical and work functioning, with $19 \%$ being able to work throughout their treatment and nearly $60 \%$ of patients taking fewer than 5 days off work, in the 63-day treatment. Temporary hair loss was seen in two patients, which was reversed after treatment stopped, in keeping with the published data (32).

The study does have several limitations. This was a retrospective study, involving carboplatin at AUC10 at a single centre. The small sample size and bias, especially ascertainment bias, which is introduced in any cohort study, limit this study. Although it is known that carboplatin does not affect fertility compared to BEP (33), this study did not look at the fertility outcomes in these patients. Future studies should also incorporate long-term cardiovascular events in carboplatin-treated patients.

\section{Conclusion}

With no relapses detected so far, this retrospective review has shown that single-agent carboplatin at AUC10 should be considered a standard treatment for patients with metastatic seminoma even at stage III. Although some relapses are to be expected with larger numbers and longer follow-up, the great majority of relapses will be salvaged by combination platinum-based chemotherapy. The excellent tolerability and efficacy of this outpatient treatment should lead to its international acceptance as first-line therapy, without the need for a large randomised trial.

\section{Funding}

The study was supported by Cancer Treatment Research Trust UK (CTRT) and CRUK grant to AS.

\section{Availability of Data and Materials}

Data sharing is not applicable to this article as no datasets were generated or analysed during the current study.

\section{Conflicts of Interest}

None to declare.

\section{Consent for Publication}

Informed consent was obtained and is available for review by the editor.

\section{References}

1 Khan O and Protheroe A: Testis cancer. Postgrad Med J 83: 624632, 2007.

2 De La Pena H, Sharma A, Glicksman C, Joseph J, Subesinghe M, Traill Z, Verrill C, Sullivan M, Redgwell J, Bataillard E, Pintus E, Dallas N, Gogbashian A, Tuthill M, Protheroe A and Hall M: No longer any role for routine follow-up chest X-rays in men with stage I germ cell cancer. Eur J Cancer 84: 354-359, 2017.

3 Warde P, Specht L, Horwich A, Oliver T, Panzarella T, Gospodarowicz $\mathrm{M}$ and von der Maase $\mathrm{H}$ : Prognostic factors for relapse in stage I seminoma managed by surveillance: a pooled analysis. J Clin Oncol 20: 4448-4452, 2002.

4 Bamberg M, Schmidberger H, Meisner C, Classen J, Souchon R, Weinknecht S, Schorcht J, Walter F, Engenhart-Cabillic R, Schulz U, Born H and Flink M: Radiotherapy for stages I and IIA/B testicular seminoma. Int J Cancer 83: 823-827, 1999.

5 Horwich A, Dearnaley DP, A'Hern R, Mason M, Thomas G, Jay $\mathrm{G}$ and Nicholls $\mathrm{J}$ : The activity of single-agent carboplatin in advanced seminoma. Eur J Cancer 28A: 1307-1310, 1992.

6 de Wit R, Stoter G, Kaye SB, Sleijfer DT, Jones WG, ten Bokkel Huinink WW, Rea LA, Collette L and Sylvester R: Importance of bleomycin in combination chemotherapy for good-prognosis testicular nonseminoma: A randomized study of the European Organization for Research and Treatment of Cancer Genitourinary Tract Cancer Cooperative Group. J Clin Oncol 15: 1837-1843, 1997.

7 Saxman SB, Finch D, Gonin R and Einhorn LH: Long-term follow-up of a phase III study of three versus four cycles of bleomycin, etoposide and cisplatin in favorable-prognosis germcell tumors: The Indian University experience. J Clin Oncol 16: 702-706, 1998.

8 Bokemeyer C, Kollmannsberger C, Stenning S, Hartmann JT, Horwich A, Clemm C, Gerl A, Meisner C, Ruckerl CP, Schmoll HJ, Kanz L and Oliver T: Metastatic seminoma treated with either single.agent carboplatin or cisplatin-based combination chemotherapy: A pooled analysis of two randomised trials. B J Cancer 91: 683-687, 2004.

9 Tookman L, Rashid S, Matakidou A, Phillips M, Wilson P, Ansell W, Jamal-Hanjani M, Chowdhury S, Harland S, Sarwar N, Oliver T, Powles T and Shamash J: Carboplatin AUC 10 for IGCCCG good prognosis metastatic seminoma. Acta Oncol 52: 987-993, 2013.

10 Gholam D, Fizazi K, Terrier-Lacombe MJ, Jan P, Culine S and Theodore C: Advanced seminoma--treatment results and prognostic factors for survival after first-line, cisplatin-based chemotherapy and for patients with recurrent disease: A singleinstitution experience in 145 patients. Cancer 98: 745-752, 2003.

11 Mencel PJ, Motzer RJ, Mazumdar M, Vlamis V, Bajorin DF and Bosl GJ: Advanced seminoma: treatment results, survival and prognostic factors in 142 patients. J Clin Oncol 12: 120-126, 1994. 
12 Heidenreich A and Hofmann R: Quality-of-life issues in the treatment of testicular cancer. World J Urol 17: 230-238, 1999.

13 Arai Y, Kawakita M, Hida S, Terachi T, Okada Y and Yoshida O: Psychosocial aspects in long-term survivors of testicular cancer. J Urol 155: 574-578, 1996.

14 Carpentier MY, Fortenberry JD, Ott MA, Brames MJ and Einhorn LH: Perceptions of masculinity and self-image in adolescent and young adult testicular cancer survivors: implications for romantic and sexual relationships. Psychooncology 20: 738-745, 2011.

15 Carpentier MY and Fortenberry JD: Romantic and sexual relationships, body image and fertility in adolescent and young adult testicular cancer survivors: A review of the literature. J Adolesc Health 47: 115-125, 2010.

16 Edge SB and Compton CC: The American Joint Committee on Cancer: the 7th edition of the AJCC cancer staging manual and the future of TNM. Ann Surg Oncol 17: 1471-1474, 2010.

17 Eisenhauer EA, Therasse P, Bogaerts J, Schwartz LH, Sargent D, Ford R, Dancey J, Arbuck S, Gwyther S, Mooney M Rubinstein L, Shankar L, Dodd L, Kaplan R, Lacombe D and Verweij J: New response evaluation criteria in solid tumours: Revised RECIST guideline (version 1.1). Eur J Cancer 45: 228247, 2009

18 Fleming JS, Zivanovic MA, Blake GM, Burniston M, Cosgriff PS and British Nuclear Medicine S: Guidelines for the measurement of glomerular filtration rate using plasma sampling. Nucl Med Commun 25: 759-769, 2004.

19 Schwartz LH, Litiere S, de Vries E, Ford R, Gwyther S, Mandrekar S, Shankar L, Bogaerts J, Chen A, Dancey J, Hayes W, Hodi FS, Hoekstra OS, Huang EP, Lin N, Liu Y, Therasse P, Wolchok JD and Seymour L: RECIST 1.1-Update and clarification: From the RECIST committee. Eur J Cancer 62: 132-137, 2016.

20 Basch E, Reeve BB, Mitchell SA, Clauser SB, Minasian LM, Dueck AC, Mendoza TR, Hay J, Atkinson TM, Abernethy AP, Bruner DW, Cleeland CS, Sloan JA, Chilukuri R, Baumgartner P, Denicoff A, St Germain D, O'Mara AM, Chen A, Kelaghan J, Bennett AV, Sit L, Rogak L, Barz A, Paul DB and Schrag D: Development of the National Cancer Institute's patient-reported outcomes version of the common terminology criteria for adverse events (PRO-CTCAE). J Natl Cancer Inst 106(9): dju244, 2014.

21 Bokemeyer C, Berger CC, Hartmann JT, Kollmannsberger C, Schmoll HJ, Kuczyk MA and Kanz L: Analysis of risk factors for cisplatin-induced ototoxicity in patients with testicular cancer. Br J Cancer 77: 1355-1362, 1998.

22 Reddel RR, Kefford RF, Grant JM, Coates AS, Fox RM and Tattersall $\mathrm{MH}$ : Ototoxicity in patients receiving cisplatin: Importance of dose and method of drug administration. Cancer Treat Rep 66: 19-23, 1982.

23 Kopelman J, Budnick AS, Sessions RB, Kramer MB and Wong GY: Ototoxicity of high-dose cisplatin by bolus administration in patients with advanced cancers and normal hearing. Laryngoscope 98: 858-864, 1988.
24 Zagars GK, Ballo MT, Lee AK and Strom SS: Mortality after cure of testicular seminoma. J Clin Oncol 22: 640-647, 2004.

25 Horwich A, Fossa SD, Huddart R, Dearnaley DP, Stenning S, Aresu M, Bliss JM and Hall E: Second cancer risk and mortality in men treated with radiotherapy for stage I seminoma. Br J Cancer 110: 256-263, 2014.

26 Garcia-del-Muro X, Maroto P, Guma J, Sastre J, Lopez Brea M, Arranz JA, Lainez N, Soto de Prado D, Aparicio J, Piulats JM, Perez X and Germa-Lluch JR: Chemotherapy as an alternative to radiotherapy in the treatment of stage IIA and IIB testicular seminoma: A Spanish Germ Cell Cancer Group Study. J Clin Oncol 26: 5416-5421, 2008.

27 Matakidou A, Mutsvangwa K, Ansell W, Lim L, Powles TB, Oliver RT and Shamash J: Single-agent carboplatin AUC10 for metastatic seminoma with IGCCCG good prognosis disease; a feasibility study of the Orchid Clinical Trials Group. Ann Oncol 21: 1730-1731, 2010.

28 Horwich A, Oliver RT, Wilkinson PM, Mead GM, Harland SJ, Cullen MH, Roberts JT, Fossa SD, Dearnaley DP, Lallemand E, Stenning SP and Party MRCTTW: A medical research council randomized trial of single-agent carboplatin versus etoposide and cisplatin for advanced metastatic seminoma. MRC Testicular Tumour Working Party. Br J Cancer 83: 1623-1629, 2000.

29 Krege S, Boergermann C, Baschek R, Hinke A, Pottek T, Kliesch S, Dieckmann KP, Albers P, Knutzen B, Weinknecht S, Schmoll HJ, Beyer J, Ruebben H and German Testicular Cancer Study G: Single-agent carboplatin for CS IIA/B testicular seminoma. A phase II study of the German Testicular Cancer Study Group (GTCSG). Ann Oncol 17: 276-280, 2006.

30 Domont J, Massard C, Patrikidou A, Bossi A, de Crevoisier R, Rose M, Wibault P and Fizazi K: A risk-adapted strategy of radiotherapy or cisplatin-based chemotherapy in stage II seminoma. Urol Oncol 31: 697-705, 2013.

31 Oliver RTD, Powles T, Ell PJ, Somasundram U and Shamash J: 22-Year phase 1/2 study of single agent carboplatin in metastatic seminoma: Potential for acceleration by a new surrogate end point, 72 hr PET scan response? J Clin Oncol 24: 14565, 2006.

32 de Jonge ME, Mathot RA, Dalesio O, Huitema AD, Rodenhuis $\mathrm{S}$ and Beijnen JH: Relationship between irreversible alopecia and exposure to cyclophosphamide, thiotepa and carboplatin (CTC) in high-dose chemotherapy. Bone Marrow Transplant 30: 593-597, 2002.

33 Ghezzi M, Berretta M, Bottacin A, Palego P, Sartini B, Cosci I, Finos L, Selice R, Foresta C and Garolla A: Impact of BEP or carboplatin chemotherapy on testicular function and sperm nucleus of subjects with testicular germ cell tumor. Front Pharmacol 7: 122, 2016.
Received October 15, 2018

Revised October 26, 2018

Accepted November 1, 2018 